\title{
Crescimento e desenvolvimento aplicado à Educação Física e ao Esporte
}

Dartagnan Pinto GUEDES*
*Centro de Educação Física e Esporte, Universidade Estadual de Londrina.

\section{Resumo}

Crescimento refere-se essencialmente às transformações progressivas de cunho quantitativas que ocorrem nas dimensões do corpo humano, enquanto desenvolvimento engloba simultaneamente transformações quantitativas e qualitativas, sendo resultante de aspectos associados ao próprio processo de crescimento físico, à maturação biológica e, especificamente no caso da Educação Física e do Esporte, ao desempenho motor. Profissionais de Educação Física e Esporte se encontram em posição privilegiada para acompanhar indicadores de crescimento e desenvolvimento, considerando seu envolvimento com aspectos educacionais e de promoção da saúde na população jovem. 0 objetivo deste estudo de revisão foi apresentar conceitos básicos e atual estado-da-arte associado ao tema crescimento e desenvolvimento aplicado à pesquisa e à prática profissional na área de Educação Física e Esporte.

UnItermos: Crescimento físico; Maturação biológica; Desempenho motor; Crianças; Jovens.

\section{Introdução}

O ser humano não é biologicamente estático. Desde o momento da concepção até a morte, é por demais conhecida a ocorrência de transformações quantitativas e qualitativas, quer no sentido evolutivo quer no involutivo. Durante as duas primeiras décadas de vida, a principal atividade do organismo humano é "crescer" e "desenvolver-se", fenômenos simultâneos e condicionados à maior ou à menor velocidade do processo maturacional e de sua interação com indicadores do ambiente.

Por conta da existência de forte interação entre o crescimento e o desenvolvimento, muitas vezes ambos os conceitos vêm sendo empregados de forma indiscriminada com o mesmo significado. Todavia, crescimento e desenvolvimento referem-se a processos que, embora indissociáveis e cuja ocorrência isolada é impossível, são fenômenos diferentes que sempre demonstram correspondência direta entre si.

Por definição, crescimento corresponde ao processo resultante da multiplicação e da diferenciação celular que determina alteraçōes progressivas nas dimensões do corpo inteiro ou de partes e segmentos específicos, em relação ao fator tempo, do nascimento à idade adulta. Em contrapartida, o desenvolvimento caracteriza-se pela sequência de modificações evolutivas em órgãos e sistemas do organismo humano que induzem ao aperfeiçoamento de suas complexas funções. Desse modo, o crescimento refere-se essencialmente às transformações quantitativas, enquanto o desenvolvimento engloba simultaneamente tanto as transformaçóes quantitativas quanto as qualitativas e é resultante de aspectos associados ao próprio processo de crescimento físico, à maturação biológica e às experiências vivenciadas no atributo considerado: desempenho motor, emocional, social, cognitivo, etc. (Roche \& Sun, 2003).

Por consequência, considera-se que desenvolvimento apresenta conceito mais abrangente que crescimento; contudo, com base em pressupostos associados às inter-relações entre atributos morfológicos e funcionais, verifica-se que indicadores de crescimento físico definem-se como pré-requisitos para a otimização do processo de desenvolvimento no organismo jovem; sobretudo no que se refere ao desempenho motor. Portanto, a monitoração do crescimento físico em crianças e adolescentes torna-se consensualmente aceita como sensível instrumento de utilização singular na aferição das condiçốes predisponentes voltadas à maximização do desenvolvimento orgânico. 
A influência de componentes genéticos na determinação dos níveis de crescimento físico parece ser indiscutível. Entretanto, faz-se necessário considerar que fatores ambientais como alimentação, atividade física, estímulos psicossociais, patologias debilitantes e aspectos básicos de saúde pública podem modificar desfavoravelmente o que o patrimônio genético estabeleceu como predeterminante (EVELETH \& TANNER, 1990).

Em vista disso, para a Organização Mundial da Saúde, níveis de crescimento físico de jovens podem ser considerados importantes indicadores de saúde e qualidade de vida individual e coletiva de uma comunidade (WHO, 1995). Em vista disso, um programa regular de acompanhamento de indicadores associados ao crescimento físico poderá auxiliar na detecção de eventuais agressōes relacionadas à saúde de crianças e adolescentes. Nesse particular, os profissionais de Educação Física e de Esporte se encontram em posição privilegiada para a função, à vista de seu significativo envolvimento com aspectos educacionais e de promoção da saúde na população jovem. Longe de diagnosticar problemas relacionados aos distúrbios de crescimento físico, as informaçôes coletadas por esses profissionais poderão auxiliar na identificação de fatores ambientais que, possivelmente, venham, na sequência, induzir a alguma disfunção relativa à saúde (DobBINs, DeCorby, Robeson, Husson \& Tirilis, 2009).

\section{Monitoração do crescimento físico}

A antropometria, técnica sistematizada utilizada para medir dimensões corporais, é o recurso empregado na monitoração do crescimento físico. A técnica antropométrica caracteriza-se como metodologia originalmente desenvolvida por antropologistas físicos; hoje, no entanto, vem sendo utilizada e aprimorada também por profissionais vinculados a várias outras áreas. Tecnicamente, as medidas antropométricas devem ser realizadas com instrumentos específicos e procedimentos rigorosamente padronizados e preferencialmente determinados nos limites de erros de medidas conhecidos.

As opções de medidas antropométricas possíveis de serem realizadas no corpo de um jovem são quase ilimitadas. Para escolha das medidas, contudo, devem-se levar em consideração fundamentalmente os propósitos da monitoração do crescimento físico. Por exemplo, o biologista humano, preocupado com a relação causaefeito dos fatores fisiológicos e ecológicos, deverá estar interessado em determinada série de medidas; o engenheiro de "design", preocupado com a construção de equipamentos ou vestimentas, deverá estar interessado em outra série de medidas; e o profissional de Educação Física e Esporte, preocupado com a interação de fatores ambientais no desenvolvimento de atributos biológicos no organismo jovem, deverá interessar-se por uma terceira série de medidas. Por consequência, em determinados momentos algumas medidas antropométricas podem ser comuns a diferentes tipos de análise do crescimento físico; outras medidas antropométricas, porém, podem ser específicas de determinada área de atuação (CAMERON, 1998).

Por questão de conveniência, para o profissional de Educação Física e Esporte o crescimento físico pode ser visualizado e analisado com base em um grupo restrito de medidas antropométricas que apresentam alguma relação entre si, considerando a similaridades de seus aspectos biológicos. Em relação ao tamanho corporal, aquelas dimensões obtidas com base no eixo longitudinal do corpo são as mais indicadas, considerando-se a estatura como principal medida, apesar de outras medidas antropométricas serem também frequentemente utilizadas, como é o caso da altura de diferentes segmentos; sobretudo a altura tronco-cefálica.

O crescimento físico relacionado ao tamanho corporal também pode ser analisado com indicadores da largura do corpo. Trata-se, nesse caso, de medidas realizadas no plano perpendicular ao eixo longitudinal. Diâmetros biacromiais e bicrista-ilíacos são as medidas antropométricas mais empregadas para esse fim por refletirem alteraçôes internas muito complexas na arquitetura da regiāo dos ombros e dos quadris. Quando se deseja obter informaçōes sobre a estimativa do crescimento de ossos específicos, devem-se também incluir medidas de comprimento e diâmetros das extremidades dos ossos envolvidos. Nesse particular, com relação aos membros inferiores, destacam-se o comprimento da coxa e da perna e os diâmetros biepicondilar do fêmur e bimaleolar. A respeito dos membros superiores, têm primazia os comprimentos do braço e do antebraço e os diâmetros biepicondilar do úmero e biestilóide.

Outro grupo de medidas antropométricas com características biológicas bem diferentes das anteriores são aquelas relacionadas aos perímetros. Com exceção do perímetro cefálico, comumente utilizado no acompanhamento do desenvolvimento das estruturas 
cerebrais em crianças nos primeiros meses de vida, as demais medidas de perímetros devem ser empregadas com alguma cautela em razão de incluírem participação simultânea de dimensões associadas tanto ao tecido ósseo como muscular, circundada por camada de gordura subcutânea. Ou seja, não apresentam definição clara com relação à participação de um único tecido por si só em suas dimensōes. No entanto, considerando que nos casos das medidas de perímetros realizadas em determinados pontos anatômicos localizados nos membros superiores e inferiores, o tecido muscular pode apresentar importante participação em suas dimensões, ocasionalmente tem-se recorrido aos perímetros do braço, do antebraço, da coxa e da perna como indicadores do crescimento físico associado ao tecido muscular.

Espessuras de dobras cutâneas são medidas antropométricas que também podem oferecer importantes informações sobre o crescimento físico de crianças e adolescentes. Suas dimensões procuram apresentar indicaçôes sobre a disposição da gordura corporal localizada nas regiōes subcutâneas. As duas medidas de espessura de dobras cutâneas mais comumente empregadas na monitoração do crescimento físico são destacadas nas regiões tricipital e subescapular.

A principal medida do crescimento físico com base na massa corporal é, naturalmente, o peso corporal. No entanto, precauçôes devem ser tomadas quando da interpretação de seus valores tendo em vista que, diferentemente das demais medidas antropométricas consideradas, as dimensões do peso corporal são resultantes da participação de diferentes constituintes corporais como ossos, músculos, gorduras e tecidos residuais. Portanto, para se obterem informaçôes mais precisas sobre o crescimento físico em relação à massa corporal, os valores do peso corporal devem vir acompanhados de outras informações que procurem identificar a proporção dos diferentes constituintes corporais.

Além de considerar cada informação isoladamente, algumas medidas antropométricas podem ser relacionadas umas com as outras mediante determinação dos chamados índices corporais, que fornecem informaçôes adicionais de considerável importância para análise do crescimento físico.

\section{Análise das medidas antropométricas}

Apesar de ser possível estabelecer quase ilimitada sequência de medidas antropométricas na tentativa de traduzir o crescimento físico, especialistas da área apontam com unanimidade a estatura e o peso corporal como principais indicadores. Essa posição justifica-se considerando que a estatura e o peso corporal, mesmo admitindo-se suas limitações para tais finalidades, caracterizam-se como principais indicadores antropométricos associados às variações das dimensóes lineares e à massa de todo o corpo. Em vista disso, para a maioria dos interesses voltados à monitoração do crescimento físico sugere-se a utilização de informações sobre o peso corporal para idade e sexo (peso corporal//idade), a estatura para idade e sexo (estatura//idade) e o peso corporal para estatura e sexo (peso corporal//estatura).

Com relação à análise das medidas antropométricas associadas ao crescimento físico, informaçôes a respeito da estatura e do peso corporal devem ser interpretadas com referenciais normativos. Nesse particular, referenciais normativos são propostos com base em levantamentos populacionais cujos sujeitos têm oportunidade de desenvolver plenamente todo o potencial de crescimento físico sem agressóes ambientais significativas que possam interferir negativamente nesse processo.

O que tem sido observado, portanto, é a utilização de resultados estatísticos provenientes de levantamentos de populações que, em princípio, tiveram as melhores oportunidades de alcançar todas as possibilidades genotípicas de crescimento, como é o caso das populações sadias de regiōes desenvolvidas ou de grupos populacionais pertencentes a estratos socioeconômicos elevados de países em desenvolvimento.

Outro aspecto importante a ser levado em conta a respeito dos referenciais normativos voltados à monitoração do crescimento físico é que estes podem sofrer variações com o decorrer do tempo por causa das mudanças nas condições de vida da população. Nesse particular, evidências disponibilizadas na literatura sugerem que, em países desenvolvidos ou em desenvolvimento, crianças e adolescentes têm crescido mais rapidamente durante as últimas décadas e atingem, para cada idade, medidas de estatura e de peso corporal sucessivamente maiores graças ao fenômeno da aceleração secular do crescimento físico (UlJASZEK, 1998). Enquanto a ação de tendências como esta estiver sendo registrada 
em determinada população, recomenda-se que os referenciais normativos associados ao crescimento físico sejam redefinidos a cada 10 ou 15 anos.

Estudos com crianças e adolescentes de diferentes regiōes do mundo têm procurado mostrar a possibilidade de utilização de um único referencial normativo para monitoração do crescimento físico. Existem evidências de que jovens saudáveis de mesma idade e sexo, quando submetidos a condiçôes adequadas de vida, mesmo pertencentes a diferentes origens étnicas, podem apresentar medidas de estatura e de peso corporal similares. Comparaçóes de dados antropométricos provenientes de países industrializados com os de países subdesenvolvidos mostram que as diferenças das condições socioeconômicas podem ser responsáveis por variaçôes de crescimento físico em maior grau (12\% de variação para as medidas de estatura e 30\% para as medidas de peso corporal) que diferenças étnicas (variaçôes de 3 a $5 \%$ respectivamente para as medidas de estatura e de peso corporal) (EVELETH \& TANNER, 1990).

Estudo de grande porte elaborado com finalidade de propor referenciais normativos voltados à monitoração do crescimento físico vem sendo desenvolvido periodicamente pelo National Center for Health Statistics (NCHS). Em seu delineamento, inicialmente utilizou-se amostragem nacional norteamericana, em que foram analisadas mais de 20 mil crianças e adolescentes entre um e 18 anos de idade. Para tanto, optou-se por envolver três ciclos de coleta de dados: um terço das crianças (seis a 11 anos) foi analisado entre 1963 e 1965; outro terço (12 a 17 anos) em 1966-1970; e o restante (um a 17 anos) entre 1971 e 1974 (Hamill, Drizd \& Johnson, Reed, Roche \& Moore, 1979). Mais recentemente processou-se a atualização dessas informações na tentativa de propor novos referenciais normativos. Esses novos estudos, desenvolvidos pela Organização Mundial da Saúde (OMS), incluem dados de jovens norte-americanos e de vários outros países obtidos mediante levantamentos populacionais realizados nos anos 1990 (De OnIS, 2011; De OnIS, ONYANGO, Borghi, Siyam, Nishida \& Siekmann, 2007).

No Brasil, a única tentativa de proposição de referencias normativos voltada à monitoração do crescimento físico foi desenvolvida no início da década de 70 com base no Projeto Santo André, envolvendo a população jovem do município homônimo, na Grande São Paulo. O estudo foi realizado inicialmente com crianças com até 12 anos de idade (Marcondes, Berquó \& Yunes, 1970), e posteriormente com adolescentes de 10 a 19 anos (Marques, Marcondes, Berquó, Prandi \& Yunes, 1982). A população estudada foi classificada em quatro estratos socioeconômicos, mas apenas um deles, o de maior poder aquisitivo, foi utilizado para definição dos referenciais normativos.

No entanto, considerando-se que na comparação dos valores encontrados entre os jovens classificados no estrato socioeconômico mais elevado do estudo brasileiro com aqueles apresentados no levantamento realizado pelo NCHS, são constatadas medidas de estatura e peso corporal muito similares para todas as idades em ambos os sexos, o Ministério da Saúde vem adotando informaçōes produzidas recentemente pela OMS como referenciais normativos para a monitoração do crescimento físico da população brasileira. Como adendo, os referenciais normativos provenientes do Projeto Santo André podem estar se tornando inadequados depois de 15 anos do levantamento realizado, admitindo-se que o fenômeno da aceleração secular ainda possa estar presente entre os jovens brasileiros.

Com relação à interpretação das dimensões antropométricas voltadas à monitoração do crescimento físico, as medidas de estatura e peso corporal devem ser confrontadas com valores representativos de pontos específicos da distribuição de percentis considerada como referência para análise; ou ainda, por intermédio de estimativas associadas ao escore " $\mathrm{z}$ ", com informações sobre média e desvio-padrão da população de referência, de acordo com sexo e idade.

\section{Acompanhamento da maturação biológica}

Desde o nascimento até a idade adulta, o organismo jovem passa por uma série de estágios, o que implica grau crescente de maturação e caracteriza o processo evolutivo da espécie humana. Por definição, a maturação biológica refere-se às sucessivas modificações que se processam em determinado tecido, sistema ou função até que seu estágio final seja alcançado. Portanto, a maturação deve ser entendida como o processo de amadurecimento mediante o qual se atinge o estado maduro, ou seja, a maturidade (TANNER, 1973).

Embora o processo de amadurecimento possa estar associado à evolução do organismo ainda 
jovem - diferentemente do que ocorre com o crescimento, quando a característica principal é a hiperplasia e/ou a hipertrofia celular (aumento do número e/ou do tamanho celular) - na maturação são envolvidos processos de especialização e de diferenciação celular. É por isso que informações apenas quantitativas com relação às dimensões de atributos biológicos considerados podem não refletir os reais estágios de maturação.

Todo indivíduo atinge o estágio adulto, ou seja, maduro biologicamente nos diferentes tecidos, sistemas ou funçōes, pode, porém, apresentar diferentes níveis de crescimento físico. De maneira geral, essa é a distinção fundamental entre evolução em direção à maturidade (maturação) e dimensões corporais finais (crescimento físico).

Se, por um lado, a dinâmica dos diferentes estágios de maturação dos sistemas biológicos é semelhante em todos os indivíduos jovens, por outro podem ocorrer variaçōes individuais significativas em relação à época em que os estágios maturacionais mais avançados são atingidos. Consequentemente, torna-se possível distinguir jovens, de mesmo sexo, com maior ou menor grau de maturação que outros de mesma idade cronológica, o que leva a algumas dificuldades quando da necessidade de desenvolver análises mais confiáveis sobre o processo evolutivo das características biológicas antes de o indivíduo alcançar o estágio adulto.

Em vista disso, para o profissional de Educação Física e Esporte, além da idade cronológica, informações sobre os estágios de maturação biológica podem definir-se como de fundamental importância quando do desenvolvimento de análises de atributos associados aos aspectos morfológicos e funcionais de indivíduos jovens.

\section{Idade cronológica "versus" idade biológica}

A idade cronológica refere-se aos anos de vida do jovem em relação ao calendário civil; logo, pode ser estabelecida mediante diferenças entre determinada data e sua data de nascimento. Em contrapartida, a idade biológica corresponde ao estágio em que determinado indicador biológico se encontra em seu "continuum" maturacional; logo, oferece informaçóes sobre sua maturação biológica. Desse modo, pode-se estimar a idade biológica pela análise comparativa entre características quantitativas e qualitativas observadas no jovem sobre o indicador biológico considerado e as características esperadas em cada idade cronológica para esse mesmo indicador biológico. Idade cronológica e idade esperada para ocorrência de características maturacionais específicas não necessariamente deverão coincidir. As variações observadas quando da confrontação das características observadas e esperadas com relação à idade cronológica real e a idade cronológica em que a característica esperada do indicador biológico considerado deverá ocorrer definem o estágio maturacional do jovem.
$\mathrm{Na}$ eventualidade de a idade cronológica apresentada pelo jovem ser inferior à idade esperada para que a característica do atributo biológico considerado seja observada, considera-se que este apresenta estágio maturacional avançado. Pelo contrário, se a idade cronológica do jovem for superior à idade esperada para ocorrência do fenômeno biológico, considera-se que este apresenta estágio maturacional tardio. No caso do estágio maturacional esperado, deverá ocorrer coincidência entre a idade cronológica do jovem e a idade esperada para ocorrência do fenômeno biológico:

Informações sobre a idade biológica, se não tão simples e imediatas quanto às da idade cronológica, tornam-se de fundamental importância na análise de atributos considerados para acompanhamento dos jovens pelos profissionais de Educação Física e Esporte, na medida em que são identificadas relações de causa e efeito extremamente elevadas entre estágios de maturação biológica e indicadores morfológicos, funcionais e motores nas primeiras duas décadas de vida.

\section{Recursos utilizados para estimativa da idade biológica}

Dentre os inúmeros aspectos que se manifestam no organismo jovem e que podem traduzir diferentes estágios de maturação biológica, os indicadores utilizados devem satisfazer cinco condições: a) refletir mudanças em característica biológica específica;

b) alcançar o mesmo estágio final em todos os jovens; 
c) mostrar contínua evolução quantitativa e/ou qualitativa, de maneira que discretos estágios nesse "continuum" possam ser identificados;

d) ser aplicável durante todo o processo de maturação orgânica; e

e) ser independente de tamanho.

Ao rever literatura especializada na área (CAMERON, 1998), verifica-se que os indicadores mais comumente utilizados na identificação da maturação biológica incluem:

a) idade de erupção dos dentes temporários e permanentes - maturação dental;

b) idade de aparecimento das características sexuais secundárias - maturação sexual;

c) idade de ossificação e fusões epifisiais - maturação óssea; e

d) idade de alcance de diferentes proporçôes em relação à estatura adulta - maturação morfológica.

Estimativas sobre a maturação dental são realizadas com o acompanhamento de eventos associados ao processo de ossificação dos dentes temporários e permanentes. Em regra, até a sua formação completa são identificados três estágios de desenvolvimento da dentição: a) nível de calcificação da cúspide; b) erupção no nível do rebordo alveolar; e c) erupção clínica à altura da gengiva. Assim, com o auxílio de indicadores previamente estabelecidos para cada idade cronológica, ao identificar em que estágio de desenvolvimento da dentição temporária e/ou permanente o jovem se encontra, torna-se possível estabelecer sua idade dental.

Os indicadores utilizados na identificação dos estágios de maturação sexual estão estreitamente associados às manifestações hormonais e às mudanças fisiológicas direcionadas ao estágio adulto e, portanto, caracterizam-se como importante instrumento de medida envolvido com estimativas da idade biológica. Seus procedimentos baseiam-se na observação das características sexuais secundárias: desenvolvimento mamário e menarca em moças; desenvolvimento escrotal e da genitália em rapazes; e desenvolvimento da pilosidade pubiana tanto em moças como em rapazes.

O recurso mais indicado para análise da maturação biológica é a estimativa da idade óssea, considerando que suas informações podem ser identificadas desde os primeiros meses de vida até por volta dos 17-18 anos de idade e apresentam elevado nível de precisão e exatidão associado à coleta dos dados. As estimativas da maturação óssea baseiam-se no pressuposto de que cada osso inicia sua evolução biológica como centro primário de ossificação que sucessivamente vai-se calcificando e se remodelando até adquirir sua forma final, com fusão das epífises com o corpo do osso. A sequência e a cronologia das fusões epifisárias podem ser detectadas com recursos radiográficos de segmentos específicos do corpo. Desta forma, ao se radiografar uma região óssea os ossos cartilaginosos que ainda não se calcificaram deverão refletir imagem mais clara, e à medida que cada osso cartilaginoso vai avançando no processo de ossificação e se tornando mais denso, sua imagem vai-se apresentando mais opaca quando refletida. Como a dimensão da área ossificada do osso em questão aumenta com a maturação óssea, quanto maior a área mais opaca apresentada na radiografia, mais elevado o estágio maturacional diagnosticado. Portanto, a análise da maturação óssea está alicerçada em dois indicadores esqueléticos: a) quantidade de ossificações apresentadas pelos ossos; e b) número de fusōes epifisiárias ocorridas (GUEDES \& GUEDES, 2006).

Observações quanto à maturação morfológica implicam necessariamente o envolvimento de medidas antropométricas que procurem oferecer informaçóes relacionadas ao crescimento físico, particularmente no que se refere à estatura. Associações estatísticas entre indicadores de maturação biológica e medidas de estatura se apresentam tão acentuadas que a própria idade óssea pode ser utilizada como importante preditora na identificação do comportamento do crescimento estatural. Neste particular, sob o ponto de vista esquelético, quanto mais avançado o estágio maturacional, mais próximo da estatura adulta se encontra o jovem. A análise dos aspectos maturacionais com os recursos da maturação morfológica torna-se mais atrativa em razão de o acesso às medidas antropométricas ser relativamente mais simples e menos invasivo que outros indicadores.

Registros na literatura apresentam três opções em que as medidas da estatura podem ser empregadas como indicadores de maturação morfológica. A primeira, mediante verificação da idade, em anos e meses, com que a estatura observada do jovem se iguala à estatura esperada para sua idade cronológica e sexo, indicada por tabelas de referência normativa relacionada ao crescimento físico. A identificação da idade cronológica com que ocorre o pico máximo de velocidade de crescimento da estatura (PVE) tem-se caracterizado como outra opção associada à maturação morfológica. Para tanto, torna-se necessário envolver o jovem em sucessivas medidas de estatura por vários anos, em intervalos de tempo regulares, com o fim de estabelecer a curva de velocidade individual direcionada à definição do início, da intensidade e da duração do crescimento máximo da estatura. A 
terceira opção empregada para análise da maturação morfológica refere-se à determinação da proporção da medida da estatura presente do jovem, estabelecida em determinada idade cronológica, em relação à própria medida da estatura final adulta predita. Esta técnica obviamente requer conhecimento quanto à medida da estatura final adulta predita do jovem, a qual pode ser estimada mediante análise radiográfica de epífises ósseas ou por intermédio de modelos matemáticos que envolvam informações quanto à estatura dos pais (RoCHE, WAINER \& ThissEN, 1975). Neste caso, chama-se atenção para o fato de que todo processo de predição deverá gerar erro de estimativa associado; portanto, na determinação da estatura final adulta predita não se pode deixar de reconhecer eventual presença desses erros de estimativa de alguma magnitude.

Em relação à interdependência dos indicadores de maturação biológica utilizados, não se pode ignorar que nem todos os indicadores apresentam

\section{Desempenho motor}

Infância e adolescência são períodos críticos, extremamente importantes, associados aos aspectos de conduta e de solicitação motora. Nessa fase do desenvolvimento humano, além das implicações de cunho fisiológico relacionadas aos aspectos de maturação biológica, o organismo jovem encontra-se especialmente sensível à influência de fatores ambientais e comportamentais tanto de natureza positiva como negativa. Assim sendo, o acompanhamento dos índices de desempenho motor de crianças e adolescentes poderá contribuir de forma decisiva na tentativa de promover a prática de atividade física no presente e para toda a vida. ritmo maturacional na mesma velocidade. Por exemplo, até o final da primeira década de vida o fenômeno biológico relacionado à erupção dos dentes permanentes já está bem avançado; contudo, características sexuais secundárias apresentam-se, nesse momento, em fase de franca imaturidade, muito mais distante do estágio adulto que a dentição. Assim, por apresentarem origens embrionárias diferentes, a maturação dental e a maturação óssea são substancialmente independentes uma da outra. Por outro lado, identificam-se outros indicadores de maturação biológica que podem se associar entre si; sobretudo na puberdade. Nesse particular, estágios mais avançados sobre as características sexuais secundárias (maturação sexual), à idade com que várias proporções da estatura adulta são alcançadas (maturação morfológica) e à idade com que diferentes fusões epifisiais são completadas (maturação óssea) estão fortemente relacionados (TANNER, 1986).
O acompanhamento dos índices de desempenho motor em adultos não está totalmente descartado; contudo, em razão do perfil biológico apresentado, oferece informações extremamente limitadas e de menor aplicabilidade quando de análises das capacidades motoras. Recomenda-se que prováveis indicações dos atributos relacionados ao desempenho motor sejam estabelecidas o mais precocemente possível, com o fim de assegurá-los em níveis esperados até que o processo de maturação biológica possa completar todo o seu potencial de desenvolvimento.

\section{Modelos de classificação das capacidades motoras}

Por meio das informações disponíveis na literatura, percebe-se a existência de variadas formas de classificação e ordenamento das capacidades motoras. Apesar de as diferentes propostas procurarem buscar fundamentação em princípios fisiológicos similares e, portanto, não apresentarem divergências conceituais notáveis entre si, considerando a inter-relação entre os atributos motores, a proposição de rotinas de monitoração do desempenho motor depende fundamentalmente do modelo de classificação das capacidades motoras considerado.
Os modelos tradicionalmente empregados na classificação das capacidades motoras procuram reunir as informações em dois segmentos claramente definidos: aquelas pertencentes ao grupo das capacidades motoras condicionantes e as que se identificam com o grupo das capacidades motoras coordenativas. O primeiro grupo é constituído pelo conjunto de capacidades motoras que apresenta como fator primordial as características da ação muscular, a disponibilidade de energia biológica e, por conseguinte, as condiçôes orgânicas do jovem. 
No segundo grupo, o das capacidades motoras coordenativas, o ponto central refere-se aos processos de controle motor, responsável pela organização e formação dos movimentos.

Desse modo, as capacidades motoras condicionantes identificam-se com atributos associados à resistência, à força, à velocidade e às suas combinações. Por outro lado, as capacidades motoras coordenativas se fundamentam na assunção, na elaboração e no processamento de informaçôes e no controle da execução dos movimentos por meio dos analisadores táteis, visuais, acústicos, estático-dinâmicos e cinestésicos.

Por vezes, os atributos relacionados à velocidade podem ser considerados como capacidade motora intermediária e não propriamente condicionante, tendo em vista que, quando solicitados, pode não existir predomínio de fatores energéticos limitantes, senão estreita relação e influência de mecanismos regulativos e, portanto, coordenativos. Os atributos decorrentes da flexibilidade também não devem ser caracterizados unicamente por fatores condicionantes ou coordenativos, mas sim pela participação de ambos.

Partindo da suposição de que o desempenho motor caracteriza-se por elevada especificidade de cada uma das capacidades motoras isoladamente e substituindo a noção de desempenho motor geral pelo conceito de que cada jovem apresenta desempenho específico em cada uma das capacidades motoras, mais recentemente surgiu outra proposição.

Esse novo modelo baseia-se no paradigma da aptidão física e classifica as capacidades motoras em componentes da aptidão física relacionada à saúde e em componentes da aptidão física relacionada ao desempenho atlético. Por essa abordagem, a aptidão física refere-se às condições que permitem ao jovem ser submetido a situaçóes que envolvem esforços físicos. Portanto, em relação à capacidade motora podem ser identificados oito componentes: resistência cardiorrespiratória, força/resistência muscular, flexibilidade, velocidade, potência, agilidade, coordenação e equilíbrio (CORBIN \& LINDSEY, 1997).

Pela óptica da aptidão física, aqueles componentes necessários à prática mais eficiente dos esportes - levando em consideração que cada especialidade esportiva pode apresentar exigências específicas - devem ser tratados como componentes da aptidão física relacionada ao desempenho atlético. A aptidão física relacionada à saúde envolve aqueles componentes que, em questóes motoras, podem ser creditados alguma proteção ao surgimento e ao desenvolvimento de disfunções degenerativas induzidas pelo estilo de vida sedentário.
Nesse contexto, a resistência cardiorrespiratória, a força/resistência muscular e a flexibilidade são componentes que caracterizam a aptidão física relacionada à saúde. Por outro lado, em adição aos componentes relacionados à saúde - que também são fundamentais na área esportiva - os componentes especificamente direcionados à aptidão física relacionada ao desempenho atlético incluem velocidade, potência, agilidade, coordenação e equilíbrio.

As capacidades motoras associadas aos componentes da aptidão física relacionada à saúde podem diferir consideravelmente das capacidades motoras identificadas com componentes relacionados ao desempenho atlético, pois esses apresentam acentuada dependência genética e demonstram elevada resistência às modificaçôes do ambiente, enquanto aqueles da aptidão física relacionada à saúde caracterizam-se por apresentar forte influência do nível de prática habitual de atividade física. Componentes específicos da aptidão física relacionada ao desempenho atlético estão também estreitamente relacionados às habilidades exigidas na prática de grande variedade de esportes.

Quando da elaboração das rotinas de monitoração do desempenho motor, torna-se extremamente importante diferenciar os componentes da aptidão física relacionada à saúde e ao desempenho atlético, considerando que a extensão de participação com que cada um desses componentes se apresenta deverá influenciar na interpretação de seus resultados. Desse modo, quando do envolvimento de jovens não-atletas, independentemente de sua idade, torna-se aconselhável envolver itens do desempenho motor que se relacionem com os três componentes da aptidão física relacionada à saúde e apenas com alguns componentes de maior representatividade associados ao desempenho atlético. No caso de jovens atletas, pelo contrário, os itens de desempenho motor abordados deverão estar relacionados com todo o rol de componentes que se identificam com o desempenho atlético.

\section{Testes motores}

De modo geral, o principal propósito de acompanhar o desempenho motor é procurar obter informaçôes do tipo quantitativo que possam propiciar comparações inter e intra-jovens com o objetivo de identificar comportamento relacionado aos aspectos de conduta e de solicitação motora. Dessa forma, em relação às estratégias de coleta das informaçōes tem-se disponível uma única opção: a administração de testes motores. 
Os testes motores caracterizam-se pela realização de uma tarefa motora conduzida em situação que procure solicitar predominantemente uma capacidade motora específica. Desse modo, um aspecto importante a considerar quando da utilização dos testes motores refere-se à necessidade de tentar estabelecer a variável fisiológica que deverá melhor relacionar-se com os resultados a serem alcançados. No entanto, essa relação não deverá ser considerada como causa e efeito, pois os resultados dos testes motores deverão envolver uma multiplicidade de fatores que não podem ser explicados apenas pelos aspectos fisiológicos.

Por sua vez, os testes motores, pelas suas características, não devem ser empregados como instrumento que possa determinar componentes fisiológicos que influenciam diretamente a capacidade motora envolvida, mas apenas para servir como indicador daquele fator fisiológico presumivelmente solicitado naquelas circunstâncias previamente elaboradas.

Em vista disso, a seleção e a administração dos testes motores deverão ser restritas àqueles que são mais sensíveis e podem responder às variações dos fatores fisiológicos desejados. Esse método exige, portanto, que estudos prévios sejam desenvolvidos a fim de serem evidenciados quais fatores fisiológicos os testes motores possam solicitar prioritariamente.

Se, por um lado, os testes motores apresentam maior facilidade quando de sua administração e têm como principal vantagem o fato de não exigirem equipamentos sofisticados e com eles ser possível obter informações com menor demanda de tempo, por outro, seu ponto fraco reside no fato de que os aspectos culturais, motivacionais e ambientais podem facilmente contaminar seus resultados.

Dessa forma, os testes motores passam a apresentar maior aplicação prática quando utilizados em avaliações comparativas de resultados de um mesmo jovem em diferentes momentos ou entre jovens que apresentem aspectos culturais e de motivação similares. Devem, portanto, ser evitadas avaliações comparativas entre resultados de testes motores administrados em jovens pertencentes a diferentes realidades em relação aos hábitos de prática de atividade física.

Ademais, quando da administração de um teste motor admite-se que a capacidade motora supostamente envolvida com esse teste apresenta interferência decisiva em sua resposta. Ao examinar seus resultados, porém, torna-se necessário ponderar que a tarefa motora definida pode demandar habilidades específicas do jovem e exigir, portanto, alguma experiência motora anterior. Consequentemente, a análise confiável da função fisiológica que possa vir a interferir na capacidade motora envolvida no teste pode ficar prejudicada.

Por intermédio das tarefas motoras, por vezes torna-se impossível isolar a participação de determinadas capacidades motoras, o que torna os resultados de alguns testes motores dependentes de mais de uma capacidade motora. Em vista disso, testes motores têm sido projetados de modo que, pela sua natureza, alguns deles podem requerer maior número de capacidades motoras que outros. No entanto, com relação à abrangência do desempenho motor, esta situação não deve tornar esses testes motores mais relevantes que os demais, tendo em vista a possibilidade de a menor especificidade de um teste motor comprometer um diagnóstico mais preciso dos níveis de desempenho motor apresentados.

No tocante à sua interpretação, os resultados provenientes dos testes motores podem ser analisados, em relação aos propósitos de análise do desempenho motor, em valores relativos e/ou absolutos. Quando a análise dos resultados for realizada com base em valores expressos em razão da própria unidade de medida, como distância, tempo, número de repetições etc., diz-se que a análise está sendo realizada em termos absolutos. No entanto, quando os resultados dos testes motores forem corrigidos por relações matemáticas, por alguma variável morfológica (peso corporal, estatura, comprimento do membro inferior etc.), diz-se que análise está sendo realizada em termos relativos.

Por conseguinte, torna-se possível que a análise do desempenho motor em relação ao sexo e à idade cronológica possa refletir comportamento específico ao se utilizarem os resultados dos testes motores em termos absolutos, mas, ao se considerarem os resultados desses mesmos testes motores em termos relativos, pode-se obter análise significativamente diferente da anterior, em razão de as variáveis morfológicas se apresentarem como fator de influência direta em seus valores. Em vista disso, sugere-se que, quando da realização de análises comparativas em relação ao desempenho motor, as diferenças entre valores absolutos e relativos devem ser consideradas.

\section{Bateria de testes motores}

Cada teste motor deverá apresentar informações com relação a grupo específico de fatores associados à determinada solicitação motora e se constituirá, portanto, em uma unidade totalmente independente dentro do rol das capacidades motoras. Por outro lado, o desempenho motor deverá ser visto como um constructo multifatorial resultante do comportamento 
apresentado pelo conjunto das capacidades motoras. Dessa forma, no que se refere à sua avaliação, parece impossível obter visão mais abrangente sobre o desempenho motor por meio da administração de um único teste motor. Em vista disto, tradicionalmente temse recorrido à utilização de baterias de testes motores para reunir em uma mesma sequência diversos testes motores, em que cada um deles deverá oferecer informaçōes sobre uma capacidade motora em particular, e, o seu conjunto, sobre o desempenho motor.

Grande variedade de baterias de testes motores tem sido idealizada e está disponível na literatura, o que permite grande número de opções quando da avaliação do desempenho motor. Todas elas apresentam em comum a preocupação em envolver um número mínimo de testes motores e uma sequência, em sua administração, em que o desgaste funcional induzido pela realização de um teste motor possa interferir minimamente nos resultados dos testes motores subsequentes. Neste particular, sugere-se que o número ideal que deve compor uma bateria de testes motores deverá estar restrito a 3-4 itens quando esta envolve componentes de aptidão física relacionada à saúde, e entre seis e oito itens quando procura privilegiar componentes de aptidão física relacionada ao desempenho atlético.

Caso a bateria de testes motores seja idealizada para ser administrada em um único dia, os testes motores que procuram oferecer informaçóes sobre a capacidade motora flexibilidade deverão iniciar a sequência. Depois, pela ordem, os testes motores que exigem participação da potência, da velocidade, da agilidade e da força/resistência muscular. Deve-se completar essa série com os testes motores que envolvem a resistência cardiorrespiratória. Caso, porém, a bateria de testes motores seja planejada de maneira que os testes motores possam ser administrados em dois dias separadamente, sugere-se que, no primeiro dia, se concentrem os testes motores que possam ser administrados "indoor", como é o caso daqueles testes motores que procuram envolver as capacidades motoras associadas à flexibilidade, à potência e à força/resistência muscular, e, no dia seguinte, os testes motores administrados em ambiente "outdoor", como os testes de caminhada/corrida de curta e longa distância.

Essa sequência para administração dos testes motores justifica-se em razão de as capacidades motoras flexibilidade, potência, velocidade e agilidade serem mais bem testadas no início de uma série de esforços físicos seguida por testes motores que procuram envolver força/resistência muscular, tendo em vista as implicaçôes fisiológicas que envolvem essas capacidades motoras. Além disso, após a administração dos testes de caminhada/corrida de longa distância recomenda-se prolongado tempo para recuperação, e, por esse motivo, sempre estes deverão ser administrados no final da sequência de testes motores de uma bateria.

Entre as baterias de testes motores localizadas na literatura, verifica-se que praticamente todas as propostas disponíveis têm em comum o fato de serem seguras contra a ocorrência de eventuais acidentes e simples na administração dos testes motores, exigirem mínimo de equipamento, permitirem a sua utilização em ambos os sexos e se ajustarem a ampla faixa etária. Infelizmente, em razão de as baterias dependerem em grande parte do protocolo com que os testes motores são administrados e considerando que seus idealizadores introduzem diferentes procedimentos na administração de alguns desses testes motores, há dificuldade, senão impossibilidade, de realização de comparações entre seus resultados, ainda que aparentemente apresentem testes motores similares.

Outro aspecto que pode comprometer comparações entre resultados de testes motores de jovens submetidos a diferentes baterias de testes refere-se às diferenças culturais entre os povos. Neste particular, o princípio básico na administração de qualquer teste motor é a tentativa de o jovem oferecer o melhor resultado possível na tarefa motora proposta. Entretanto, quando a bateria de testes motores for conduzida e não houver o devido interesse em obter os melhores resultados, a análise do desempenho motor poderá ser irreal. Além disso, em determinados testes motores os resultados são fortemente influenciados pelos hábitos de prática de atividade física que envolve movimentos exigidos no próprio teste motor.

Com relação à reprodutibilidade das baterias de testes motores, deve-se descartar a hipótese de que, se a reprodutibilidade de cada teste motor que compõe a bateria é satisfatória, a reprodutibilidade de toda a bateria de teste motor é aceitável. Com base no pressuposto de que as baterias de testes motores são compostas por vários itens destinados a fornecer informações bem distintas sobre o desempenho motor, e de que, por sua vez, as baterias de testes motores constituem instrumento único dependente tanto da disposição como da inter-relação entre os testes motores que as compóem, a reprodutibilidade das baterias de testes motores como unidade é tão importante quanto à reprodutibilidade de cada teste motor isoladamente.

A reprodutibilidade de uma bateria de testes motores tem como principal vantagem o fato de fornecer informações sobre a ocorrência de eventuais variações nos resultados encontrados em consequência da disposição de cada um dos testes 
(variação inter-testes), embora sua magnitude seja também afetada pela inconsistência dos próprios resultados dos testes individualmente (variação intra-teste). Variações inter-testes tornam-se fator importante a se considerar, na medida em que cada teste motor que compõe a bateria não é administrado independentemente do outro. Assim, o resultado de um teste motor pode influenciar o resultado de um segundo teste motor em proporção tal que este pode não ser semelhante se for administrado como se não fizesse parte integrante da bateria.

Como informação adicional, a reprodutibilidade associada à variabilidade entre réplicas de administração de bateria de testes motores pode ser estimada por meio de procedimentos de correlação canônica. Apesar de esse recurso estatístico ser bastante complexo em valores matemáticos, pode oferecer importantes informaçôes sobre a utilização de uma bateria de testes motores, como: a) a reprodutibilidade teste-reteste "ótima” da bateria de testes motores; b) a variabilidade inter e intratestes entre duas administrações da bateria de testes motores; e c) a contribuição da variação dos resultados de cada teste motor na reprodutibilidade de toda a bateria (WoOd \& SAFrit, 1987).

Infelizmente, apesar da existência de inúmeras baterias de testes motores idealizadas com intenção de avaliar o desempenho motor, verifica-se alguma dificuldade em identificar a reprodutibilidade de qualquer uma delas, numa mostra de que, quando de suas proposições, foi levada em consideração, entre outros aspectos, apenas a reprodutibilidade de cada teste motor individualmente e não a reprodutibilidade dos testes motores quando estes são administrados em conjunto com os demais.

Dentre as baterias de testes motores à disposição na literatura, com relação às capacidades motoras direcionadas à aptidão física relacionada à saúde, três delas, de origem norte-americana, vêm recebendo maior aceitação: a Physical Best, idealizada pela American Alliance for Health, Physical Education, Recreation and Dance (AAHPERD, 1988); a NCYFS (National Children and Youth Fitness Study), preconizada pelo U.S. Department of Health and Human Services (Ross \& Gilbert, 1985; Ross \& Pate, 1987); e a Fitnessgram, proposta pelo Cooper Institute for Aerobics Research (Meredith \& WelK, 2010). No que se refere às capacidades motoras identificadas com a aptidão física relacionada às capacidades atléticas, nos Estados Unidos e no Canadá destacam-se as baterias de testes motores preconizadas pela American Alliance for Health, Physical Education, Recreation and Dance (AAHPERD, 1976) e pela Canadian Association for Health, Physical Education and Recreation (CAHPERD, 1980). Em países europeus tem-se oferecido maior atenção à bateria de testes motores sugerida pelo programa Eurofit (COMMITTEE FOR THE Development of Sport, 1988). Após estudos para conciliar aspectos associados à reprodutibilidade e à garantia de qualidade das informaçôes, idealizou-se uma bateria de testes motores direcionada à avaliação do desempenho motor de jovens brasileiros (GUEDES \& Guedes, 2006).

\section{Análise dos resultados de testes motores}

Resultados de testes motores administrados com o fim de desenvolver inferências sobre o desempenho motor de jovens têm sido tradicionalmente analisados e interpretados pela confrontação com dados normativos, envolvendo referenciais idealizados com base em distribuição de percentis. Parece evidente que avaliaçóes com essas características tornam-se extremamente úteis quando a intenção é desenvolver análises intra e interavaliados, o que permite a visualização precisa da magnitude de eventuais alterações que possam ocorrer.

Abordagens desse tipo acarretam inferências sobre localização dos resultados alcançados nos testes motores diante de pontos específicos da distribuição de percentis estabelecida com base em amostras representativas de subgrupos populacionais. Contudo, diferentemente do que se preconiza quando da análise de indicadores associados ao crescimento físico - em razão da significativa participação de aspectos relacionados à interação entre fatores culturais, habilidade motora e hábitos de prática da atividade física nos resultados dos testes motores - indubitavelmente a transferência de referências normativas de uma realidade para outra se torna muito temerosa.

Nesses casos, a situação indicada é dispor de referenciais estabelecidos com base em levantamentos que procuram atender às características específicas de cada subgrupo populacional para que, fundamentalmente, os jovens, ao terem seus resultados confrontados com algum referencial, venham a apresentar características motoras bem similares às da amostra sobre a qual os referenciais normativos foram idealizados. Em vista 
disso, diferentes opçôes relativas à proposição de referenciais normativos estão disponíveis na literatura.

Apesar de ser possível reunir importantes informações com a análise dos resultados dos testes motores mediante envolvimento de referenciais normativos atualizados e adequados à realidade do jovem em questão, seus procedimentos não conseguem oferecer subsídios que possam contribuir com o fim de esclarecer se os resultados dos testes motores efetivamente evidenciam níveis satisfatórios em relação à aptidão física relacionada à saúde.

Em princípio, mesmo admitindo-se importante associação entre os indicadores mais elevados de aptidão física e as condições satisfatórias de saúde em populações jovens, análises equivalentes às posições mais elevadas na distribuição de percentis podem não garantir necessariamente condições satisfatórias de saúde, na medida em que as características da amostra da qual a distribuição de percentis foi derivada deverão afetar de maneira significativa a capacidade de detecção das diferenças.

Assim, as posições de resultados individuais podem localizar-se no extremo superior da distribuição de percentis desenvolvida em segmento específico da população que possivelmente venha a apresentar hábitos de prática de atividade física inadequados para garantir condições satisfatórias de saúde, e, ao mesmo tempo e de forma antagônica, idênticos resultados podem situar-se no extremo inferior quando confrontados com a distribuição de percentis derivada com base em segmento da população que apresenta comportamentos favoráveis ao desenvolvimento de melhores condições de saúde.

Com a introdução dos novos conceitos relacionados à aptidão física e à saúde, admite-se que, quando as diferenças entre os jovens deixam de ser importantes, as análises referenciadas por critérios deverão apresentar vantagens em relação às confrontações com dados normativos. Nestes casos, os critérios deverão representar pontos de corte identificados com indicadores de aptidão física consistentes com as condições satisfatórias de saúde, independentemente da posição em que se encontram na distribuição de percentis.

Dessa forma, ao recorrer às análises referenciadas por critérios é interessante identificar se cada jovem, individualmente, se torna capaz de alcançar pontos de corte previamente estabelecidos em relação aos indicadores de aptidão física que possam assegurar algum grau de proteção diante do aparecimento e do desenvolvimento de disfunçôes hipocinéticas.

A essência da teoria que procura justificar a proposição de pontos de corte para indicadores de aptidão física relacionada à saúde baseia-se na premissa de que, para ocorrer redução na incidência de disfunções orgânicas, torna-se necessário alcançar níveis desejáveis de resistência cardiorrespiratória, força/resistência muscular e flexibilidade que possam conter eventual processo degenerativo induzido por hábitos de vida inadequados com relação à prática de atividade física.

Em oposição ao enfoque oferecido à análise referenciada por norma - em que o objetivo é apresentar resultados equivalentes aos mais elevados valores de percentis - os jovens que não alcançam pontos de corte previamente estabelecidos como indicadores da aptidão física relacionada à saúde deverão apresentar maior predisposição aos sintomas crônico-degenerativos, enquanto os que alcançam ou excedem os pontos de corte estabelecidos demonstram menor risco neste sentido. Assim, o importante não é comparar os resultados apresentados por um jovem com outros resultados mediante valores normativos, mas sim verificar se seus resultados alcançam os pontos de corte estabelecidos em relação à saúde.

Neste particular, a maior dificuldade encontrada pelos especialistas da área se concentra na determinação de resultados associados aos indicadores de desempenho motor que possam ser utilizados como ponto de corte, garantindo níveis desejados e absolutos necessários à melhor condição de saúde. Infelizmente, tudo indica que na atualidade não existe nenhum mecanismo confiável direcionado à proposição de pontos de corte que possam assegurar, com alguma convicção, níveis mínimos requeridos à redução dos riscos de disfunções degenerativas mediante indicadores de aptidão física.

Diante dessa situação incômoda, com base em pesquisas experimentais, achados clínicos e designações arbitrárias baseadas em dados normativos observam-se algumas iniciativas direcionadas à proposição de pontos de corte relacionados aos indicadores de desempenho motor associados à aptidão física relacionada à saúde. Dois dos principais programas de diagnóstico e acompanhamento dos níveis de aptidão física relacionada à saúde em população jovem são o Physical Best (AAHPERD, 1988) e o Fitnessgram (Meredith \& WeLK, 2010).

Se, por um lado, existe consenso entre ambas as propostas quanto às estratégias de ação empregadas na proposição dos pontos de corte, por outro se constata que escores associados aos pontos de corte sugeridos na tentativa de atender idênticos testes motores não são similares. Essa discrepância ocorre em razão de discordâncias entre as duas propostas de ajustes necessários à correção da influência dos indicadores de crescimento físico e 
de maturação biológica nos resultados dos testes motores. Portanto, ao interpretar os resultados dos testes motores mediante análise referenciada por critério, faz-se necessário levar em conta que um mesmo valor, produzido por um mesmo jovem em um mesmo momento, pode receber julgamento diferente se analisado frente a uma ou a outra proposta de ponto de corte.

\section{Considerações finais}

Nos dias atuais, existe maior conscientização visando a abandonar o conceito tradicionalmente empregado para definir saúde, e desse modo, procura-se incorporar um significado mais abrangente, que permite exprimir de maneira mais adequada a multiplicidade de aspectos que a envolve. Neste sentido, saúde deve ser entendida não somente como ausência de doenças ou enfermidades, mas, sobretudo, como um estado favorável de bem-estar.

Assumindo essa concepção de saúde, é evidente que não basta apenas não estar doente; é preciso apresentar evidências, atitudes e comportamentos que afastem ao máximo possíveis fatores de risco que possam induzir ao aparecimento e ao desenvolvimento de doenças. Ao admitir que algumas doenças se manifestam no organismo muito antes de ser possível o seu diagnóstico, e seus sintomas são consequência de estágios mais avançados de agentes agressivos, não se pode considerar, por exemplo, que jovens ao apresentarem índices de crescimento físico aquém do esperado, ou quantidades de gordura corporal não compatíveis com os limites admissíveis, ou ainda,
Apesar do avanço nesse campo, desconhece-se qualquer tentativa de validação dos pontos de corte até então sugeridos. Em vista disso, deve-se levar em conta que análises de escores provenientes de testes motores mediante pontos de corte relativos aos indicadores de desempenho motor associados à aptidão física relacionada à saúde, até então disponibilizadas na literatura, deverão ser realizadas com alguma reserva.

alguma deficiência em relação ao desempenho motor, possam demonstrar estado de saúde satisfatório apenas porque, no momento, não estariam apresentando nenhum sintoma de qualquer tipo de doença.

Com isso em mente, informações relacionadas com atributos que procuram evidenciar características de crescimento físico, maturação biológica, desempenho motor e suas interaçôes, podem se constituir, reconhecidamente, em importantes indicadores do estado de saúde de uma população jovem. Logo, dentre as muitas razóes que estimulam estudiosos de todo o mundo a desenvolverem estudos nesta área, inequivocadamente estão aquelas vinculadas à preocupação de prevenção primária e promoção da saúde de crianças e adolescentes. Por esse motivo, em alguns países não é surpresa encontrar grande variedade de estudos epidemiológicos que procuram documentar, analisar e compreender aspectos relacionados ao trinômio crescimento físico - maturação biológica - desempenho motor, fazendo com que, nessas realidades, já exista uma notável tradição no desenvolvimento de açôes com essa finalidade.

\begin{abstract}
Growth and development applied to Physical Education and Sport

Growth refers essentially to progressive transformation of quantitative nature that occur in human body dimensions, while development involves both quantitative and qualitative changes, resulting from aspects related to process itself of physical growth, maturation and, specifically in the case of physical education and sport, motor performance. Professional physical education and sport are uniquely positioned to monitor indicators of growth and development, considering its involvement with educational aspects and health promotion among young people. The objective of this review study was present basic concepts and current state of the art associated with growth and development applied to research and professional practice in the area of physical education and sport.
\end{abstract}

UnITERMS: Physical growth; Maturation; Motor performance; Children; Youth. 


\section{Referências}

AMERICAN ALLIANCE FOR HEALTH, PHYSICAL EDUCATION, RECREATION AND DANCE (AAHPERD). Youth fitness test manual. Washington: AAHPERD, 1976.

Physical best. Reston: AAHPERD, 1988.

CAMERON, N. Measurement and assessment. In: ULIJASZEK, S.J.; JOHNSTON, F.E.; PREECE, M.A. The Cambridge encyclopedic of human growth and development. Cambridge: University Press, 1998.

COMMITTEE FOR THE DEVELOPMENT OF SPORT. Handbook for the Eurofit tests of physical fitness. Rome: Council of Europe, 1988.

CANADIAN ASSOCIATION FOR HEALTH, PHYSICAL EDUCATION, RECREATION AND DANCE (CAHPERD). The CAHPERD fitness-performance II test manual. Vanier: CAHPERD, 1980.

CORBIN, C.B.; LINDSEY, R. Concepts of physical fitness. 9th ed. Dubuque: Brown \& Benchmark, 1997.

De ONIS, M. New WHO child growth standards catch on. Bulletin of the World Health Organization, Geneve, v.89, p.250-1, 2011.

De ONIS, M.; ONYANGO, A.W.; BORGHI, E.; SIYAM, A.; NISHIDA, C.; SIEKMANN, J. Development of a WHO growth reference for school-aged children and adolescents. Bulletin of the World Health Organization, Geneve, v.85, p.660-7, 2007. DOBBINS, M.; DeCORBY, K.; ROBESON, P.; HUSSON, H.; TIRILIS, D. School-based physical activity programs for promoting physical activity and fitness in children and adolescents aged 8-18. Cochrane Database of Systematic Reviews, Chichester, v.1, CD007651, 2009.

EVELETH, P.B.; TANNER, J.M. Worlswide variation in human growth. 2th ed. Cambridge: University Press, 1990. GUEDES, D.P.; GUEDES, J.E.R.P. Manual prático para avaliação em educação física. São Paulo: Manole, 2006.

HAMILL, P.V.V.; DRIZD, T.A.; JOHNSON, C.L.; REED, R.B.; ROCHE, A.F.; MOORE, W.M. Physical growth: National Center for Health statistics percentiles. American Journal of Clinical Nutrition, Bethesda, v.32, p.602-29, 1979. MARCONDES, E.; BERQUÓ, E.S.; YUNES, J. Estudo antropométrico de crianças brasileiras de zero a doze anos de idade. São Paulo: Anais Nestlé, 1970.

MARQUES, R.M.; MARCONDES, E.; BERQUÓ, E.S.; PRANDI, R.; YUNES, J. Crescimento e desenvolvimento pubertário em crianças e adolescentes brasileiros. São Paulo: Brasileira de Ciências, 1982. v.2: Altura e peso.

MEREDITH, M.D.; WELK, G.J. Fitnessgram \& activitygram test administration manual-updated. 4th ed. Dallas: The Cooper Institute for Aerobics Research, 2010.

ROCHE, A.F.; SUN, S.S. Human growth: assessment and interpretation. Cambridge: University Press, 2003.

ROCHE, A.F.; WAINER, H.; THISSEN, D. The RWT method for the prediction of adult stature. Pediatrics, Springfield, v.56, p.1026-33, 1975.

ROSS, J.G.; GILBERT, G.G. The national children and youth fitness study - NCYFS: a summary of finding. Journal of Physical Education, Recreation and Dance, Reston, v.56, p.45-50, 1985.

ROSS, J.G.; PATE, R.R. The national children and youth fitness study II - NCYFS II: a summary of finding. Journal of Physical Education, Recreation and Dance, Reston, v.58, p.51-6, 1987.

TANNER, J.M. Growth at adolescence. 2th ed. Oxford: Blackwell Scientific, 1973.

. Normal growth and techniques of growth assessment. Clinical in Endocrinology and Metabolism, London, v.15, p.411-51, 1986. ULIJASZEK, S.J. Between-population differences in human growth. In: ULIJASZEK, S.J.; JOHNSTON, F.E.; PREECE, M.A. The Cambridge encyclopedic of human growth and development. Cambridge: University Press, 1998 WOOD, T.M.; SAFRIT, M.J. A comparison of three multivariate models for estimating test battery reliability. Research Quarterly for Exercise and Sport, Washington, v.58, p.150-9, 1987.

WORLD HEALTH ORGANIZATION (WHO). Physical status: the use and interpretation of anthropometry. Report of a WHO Expert Committee. WHO: Technical Report Series, v.854, p.1-452, 1995.

ENDEREÇO

Dartagnan Pinto Guedes

R. Ildefonso Werner 177 - Condomínio Royal Golf 86055-545 - Londrina - PR - BRASIL e-mail: darta@sercomtel.com.br

140 • Rev. bras. Educ. Fís. Esporte, São Paulo, v.25, p.127-40, dez. 2011 N. esp. 